\title{
Comparing Biologic Cost Per Treated Patient Across Indications Among Adult US Managed Care Patients: A Retrospective Cohort Study
}

\author{
Tao Gu ${ }^{1} \cdot$ Neel Shah ${ }^{2} \cdot$ Gaurav Deshpande ${ }^{1}$. \\ Derek H. Tang ${ }^{2} \cdot$ Debra F. Eisenberg ${ }^{1}$
}

Published online: 18 October 2016

(C) The Author(s) 2016. This article is published with open access at Springerlink.com

\begin{abstract}
Background The relative cost of biologics in the treatment of autoimmune disorders, including rheumatoid arthritis, psoriatic arthritis, psoriasis, and ankylosing spondylitis, is a key consideration for managed care payers.

Objectives Our objective was to estimate biologic costs and treatment patterns in US managed care patients with rheumatoid arthritis, psoriatic arthritis, psoriasis, and/or ankylosing spondylitis.

Methods This retrospective study used administrative claims data from the HealthCore Integrated Research Database (HIRD ${ }^{\mathrm{SM}}$ ) for adults with rheumatoid arthritis, psoriatic arthritis, psoriasis, and/or ankylosing spondylitis who received abatacept, adalimumab, certolizumab, etanercept, golimumab, infliximab, rituximab, tocilizumab, or ustekinumab between 1 July 2009 and 31 January 2013. Biologic costs (based on drug utilization) and treatment patterns (discontinued, restarted after a $>45$-day gap, switched to another biologic, or persisted without switching or stopping) were analyzed for the first year post-index.
\end{abstract}

Tao Gu

TGu@healthcore.com

1 HealthCore, Inc., 123 S. Justison Street, Suite 200, Wilmington, DE 19801-5134, USA

2 Amgen Inc., Thousand Oaks, CA, USA
Results Most of the 24,460 patients received etanercept (48\%), adalimumab (29\%), or infliximab $(12 \%)$ as the index biologic. On the index date, $44 \%$ were new to biologic therapy and $56 \%$ were continuing biologic therapy. Biologic cost per treated patient for 1 year was as follows: etanercept \$US24,859, adalimumab \$US26,537, and infliximab $\$$ US26,468. Treatment patterns across indications for etanercept, adalimumab, and infliximab were as follows: persistent $(52,49,67 \%)$, restarted (23, $21,12 \%)$, switched $(12,13,11 \%)$, and discontinued (14, $18,10 \%)$.

Conclusions These findings from a large health benefits organization in the USA are similar to those of several previous cost analyses assessing different populations, which demonstrates the external validity of the results from the previous studies, both over time and across large populations.

\section{Key Points}

Biologic claims data were analyzed for nearly 25,000 patients in managed care with rheumatoid arthritis, psoriatic arthritis, psoriasis, or ankylosing spondylitis.

Nearly $90 \%$ of index biologic claims from July 2009 to January 2013 were for adalimumab, etanercept, or infliximab; most patients were persistent on biologic therapy in the first year or restarted the index biologic after a treatment gap.

Etanercept had lower biologic costs in the first year post-index than adalimumab or infliximab across all four conditions. 


\section{Introduction}

Autoimmune disorders such as rheumatoid arthritis, psoriatic arthritis, and ankylosing spondylitis are characterized by pain and joint swelling, and-in severe cases-progressive destruction of joint tissue [1-3]. Psoriasis is characterized by patches of raised red skin covered by silvery white scale [4]. These are severe, chronic, and disabling diseases that can shorten life expectancy and impair quality of life. Biologic disease-modifying antirheumatic drugs (DMARDs) that are approved for the treatment of one or more of these chronic conditions in the USA include abatacept [5], adalimumab [6], certolizumab pegol [7], etanercept [8], golimumab [9], infliximab [10], rituximab [11], tocilizumab [12], and ustekinumab [13]. These biologics differ in their approved indications (Table 1), mechanism of action, method of administration (intravenous, subcutaneous, or both), frequency of administration, availability within health plans, immunogenicity [14-16], and approval for first-line or subsequent biologic therapy.

Relative to trials comparing active treatment against placebo, head-to-head prospective clinical trials of biologics in the treatment of autoimmune disorders are rare because a large number of patients need to be recruited to detect any differences in efficacy between biologics. In the absence of head-to-head studies to compare biologics, current evidence and reviews suggest biologics have similar efficacy [17-19]. The relative cost of biologics is thus a key consideration for managed care payers. Previous analyses that used administrative claims data through 2009, 2010, or 2011 reported that etanercept had lower costs per treated patient than adalimumab or infliximab in patients with rheumatoid arthritis, psoriatic arthritis, psoriasis, and/ or ankylosing spondylitis [20-27]. Several other studies examined biologic costs only among patients with rheumatoid arthritis. A claims-based analysis reported that etanercept and adalimumab had similar costs and infliximab had approximately $30 \%$ greater costs per treated patient with rheumatoid arthritis [28]. When an algorithm was used to estimate effectiveness retrospectively from claims data, etanercept had lower costs per effectively treated patient with rheumatoid arthritis than adalimumab or infliximab [29-31]. In some of these cost-effectiveness analyses, the cost per effectively treated patient with rheumatoid arthritis was similar between etanercept and newer biologics such as golimumab or abatacept, whereas other studies reported lower costs per effectively treated patient with etanercept than with the newer biologics; small sample sizes for newer biologics may have contributed to the inconsistent results. Rituximab had lower costs per quality-adjusted life-year than other tumor necrosis factor (TNF) inhibitors in patients with rheumatoid arthritis in an analysis that combined cost data in the UK with aggregated efficacy results across clinical studies that were published through July 2009 [32].

A majority of patients continue their assigned biologic therapy for at least 1 year, but many of these patients have gaps in biologic treatment [25-27, 33]. In clinical practice, the time between refills of self-administered biologics is

Table 1 Biologics approval dates and wholesale acquisition costs

\begin{tabular}{|c|c|c|c|c|c|}
\hline \multirow[t]{2}{*}{ Biologic } & \multicolumn{4}{|c|}{ Indication/FDA approval date } & \multirow[t]{2}{*}{ WAC $^{\mathrm{a}}$} \\
\hline & Rheumatoid arthritis & Psoriatic arthritis & Psoriasis & Ankylosing spondylitis & \\
\hline Abatacept & $\begin{array}{l}\text { Dec } 2005 \text { (IV) } \\
\text { Jul } 2011 \text { (SC) }\end{array}$ & - & - & - & $\$ 702 / 250 \mathrm{mg}$ \\
\hline Adalimumab & Dec 2002 & Oct 2005 & Jan 2008 & Jul 2006 & $\$ 2700 / 80 \mathrm{mg}$ \\
\hline Certolizumab & May 2009 & Sep $2013^{b}$ & - & Oct $2013^{b}$ & $\$ 2770 / 400 \mathrm{mg}$ \\
\hline Etanercept & Nov 1998 & Jan 2002 & April 2004 & July 2003 & $\$ 2701 / 200 \mathrm{mg}$ \\
\hline Golimumab & $\begin{array}{l}\text { Apr } 2009 \text { (SC) } \\
\text { Jul } 2013(\text { IV) }\end{array}$ & Apr 2009 & - & Apr 2009 & $\$ 2979 / 50 \mathrm{mg}$ \\
\hline Infliximab & Nov 1999 & May 2005 & Sep 2006 & Dec 2004 & $\$ 928 / 100 \mathrm{mg}$ \\
\hline Rituximab & Mar 2006 & - & - & - & $\$ 705 / 100 \mathrm{mg}$ \\
\hline Tocilizumab & $\begin{array}{l}\text { Jan } 2010 \text { (IV) } \\
\text { Oct } 2013(\text { SC) }\end{array}$ & - & - & - & $\$ 1501 / 400 \mathrm{mg}$ \\
\hline Ustekinumab & - & Sep $2013^{\mathrm{b}}$ & Sept 2009 & - & $\$ 7661 / 45 \mathrm{mg}$ \\
\hline
\end{tabular}

FDA US Food and Drug Administration, IV intravenous, $S C$ subcutaneous, WAC wholesale acquisition cost

${ }^{\text {a }}$ WAC package prices at the time of the analysis (\$US)

b Approved after the end of the study period 
longer than recommended for approximately $30 \%$ of refills [34]. In a study of Medicaid enrollees with rheumatoid arthritis who received a TNF inhibitor between 2000 and 2002, approximately $66 \%$ had at least one continuous treatment gap of $\geq 30$ days and approximately $33 \%$ had at least one continuous treatment gap of $\geq 120$ days [35], which suggests that approximately half of the patients with a treatment gap subsequently restarted the same biologic therapy. Subsequent analyses of commercially insured patients with autoimmune disorders who initiated a TNF inhibitor reported that approximately half of the patients restarted the index TNF inhibitor after a treatment gap [36-38]. It is possible that the approval of additional biologics in recent years has influenced treatment patterns by giving patients more treatment options after a gap in therapy.

The objective of this study was to estimate biologic drug costs and drug administration costs per treated patient across biologics used for rheumatoid arthritis, psoriatic arthritis, psoriasis, ankylosing spondylitis, or any combination of the four indications in US managed care patients. To examine cost trends across populations and over time, this study used data from a different health plan that is representative of the US population [39], and this study included newer claims data through 2013. Exploratory study objectives were to estimate costs per treated patient between newly initiating and continuing patients and to estimate treatment patterns across biologics.

\section{Methods}

\subsection{Data Source}

This retrospective study used methods similar to those of previous claims-based analyses of cost per treated patient [20-27] and applied those methods to administrative data from the HealthCore Integrated Research Database $\left(\right.$ HIRD $\left.^{\mathrm{SM}}\right)$. The HIRD contains longitudinal medical and pharmacy claims data from a large commercially insured population in the USA. It includes a broad and geographically diverse spectrum of patients from 14 commercial health plans distributed across the southeastern, mid-Atlantic, central, and western regions of the USA. Data contained within the HIRD at the end of the study period in this analysis covered approximately 50 million patient lives.

\subsection{Patient Selection Criteria}

Patients were included in the analysis if they met all of the following inclusion criteria: at least one claim for abatacept, adalimumab, certolizumab, etanercept, golimumab, infliximab, rituximab, tocilizumab, or ustekinumab between 1 July 2009 and 31 January 2013; age 18-63 years on the index date (i.e., the date of the first biologic claim that satisfied all other criteria); continuous enrollment from 180 days pre-index to 360 days post-index; and at least one diagnosis pre-index for rheumatoid arthritis (International Classification of Diseases, 9th revision, clinical modification [ICD-9-CM] code 714.xx), psoriatic arthritis (696.0x), psoriasis (696.1), or ankylosing spondylitis (720.0x).

Patients were excluded from the analysis if they met any of the following exclusion criteria: claims for more than one biologic of interest on the index date (another biologic could be used during the pre-index period but only one biologic was permitted on the index date); an index claim for a biologic before it had US FDA approval for the indication (Table 1); at least one diagnosis pre-index for Crohn's disease (555.xx), ulcerative colitis (556.xx), juvenile idiopathic arthritis (714.3x), non-Hodgkin's lymphoma (200.xx, 202.xx), or chronic lymphocytic leukemia (ICD-9: 204.1x); a biologic dose greater than twice the approved maximum dose for any indication; a Healthcare Common Procedure Coding System (HCPCS) J-code for a self-administered (subcutaneous) biologic; a National Drug Code (NDC) prescription claim for an intravenous biologic; or \$USO cost and billed units on claim lines.

\subsection{Outcome Measures}

\subsubsection{Cost per Treated Patient in the First Year Post-Index}

Cost per treated patient in the first year post-index for each biologic was determined from the payer perspective and calculated as total costs in the first year post-index for an index biologic divided by the number of patients treated with the index biologic. Total biologic costs included the total biologic drug and associated administration costs in the first year post-index, based on the actual drug utilization and drug administrations, multiplied by standardized costs from established sources, as follows:

\section{Total biologic costs $=$ (total biologic drug utilization}

$\times$ wholesale acquisition cost) + (number of biologic

administrations $\times$ unit administration cost)

- patient coinsurance/copay + dispensing fee.

Drug prices were based on wholesale acquisition cost (WAC) as of 5 November 2014, which were the most recent data available at the time of the analysis (Table 1). Unit administration cost of injection/infusion administration was based on the Medicare Fee Schedule as of 1 October 2014, where the cost of intravenous administration was \$US133 for the first hour and \$US28 for each additional hour and the cost of the first subcutaneous injection was \$US25 (subsequent injections were assumed to be self-administered at no cost). 
Patient coinsurance/copay was $19 \%$ for intravenous biologics and \$US51 for subcutaneous biologics, and dispensing fees were \$US0 and \$US3, respectively, for intravenous and subcutaneous biologics, based on national averages.

Costs for restarting index therapy or switching to another biologic (and the associated biologic drug administration costs for these subsequent therapies) were attributed to the index biologic. This approach was used to avoid underestimation of total costs to the payer among patients for whom the index biologic failed and required a switch to a different therapy. Claims that occurred after the 360-day post-index period were not included in the analysis.

\subsubsection{Treatment Patterns}

Treatment patterns for the index biologic in the 1-year (360day) post-index period were categorized as discontinued, switched, restarted, or persisted. A patient discontinued the index biologic if, after a $>45$-day refill gap for the index biologic, the patient had no claim for any biologic of interest for the remainder of the post-index period. A patient switched the index biologic if a non-index biologic of interest was initiated during the post-index period and the index biologic was discontinued. A patient restarted the index biologic if, after a >45-day refill gap for the index biologic, the patient had another claim for the index biologic during the post-index period. A patient persisted on the index biologic if none of the above criteria were met (i.e., the patient remained on the index biologic throughout the post-index period with neither a $>45$ day refill gap nor a switch in biologic).

\subsection{Statistical Methods}

Patients were stratified by their index biologic, indication, or combination of indications (rheumatoid arthritis plus psoriatic arthritis, psoriasis plus psoriatic arthritis, or any other combination) and whether they were new to biologic therapy (no claim for the index biologic in the pre-index period) or continuing biologic therapy (one or more claim for the index biologic in the pre-index period). The average cost per treated patient in the first year post-index (see Sect. 2.3.1) and the frequency and proportion of each category of treatment patterns were computed for each cohort. As this was a descriptive study, no formal statistical comparisons were conducted.

\section{Results}

\subsection{Study Sample}

The analysis included 24,640 patients after inclusion and exclusion criteria were applied (Fig. 1). The most commonly prescribed biologics across indications were etanercept $(11,771 ; 48 \%)$, adalimumab $(7223 ; 29 \%)$, and infliximab $(3036 ; 12 \%)$, followed by abatacept $(851 ; 3 \%)$, rituximab $(551 ; 2 \%)$, ustekinumab $(466 ; 2 \%)$, golimumab $(454 ; 2 \%)$, certolizumab (186; $1 \%)$, and tocilizumab (102; $<1 \%)$.

Baseline characteristics are provided in Table 2. Mean age for patients in each of the indications ranged from 45 to 51 years; more than half of the patients were women for all biologics except ustekinumab (46\% women); approximately two-thirds of patients were enrolled in a preferred provider organization (PPO) health plan and one-quarter were enrolled in a health maintenance organization (HMO) health plan. A total of 10,823 (44\%) patients were new to biologic therapy and 13,817 (56\%) were continuing biologic therapy; the proportion of patients who were continuing ongoing treatment with the individual biologics on the index date ranged from $23 \%$ (rituximab) to $72 \%$ (infliximab).

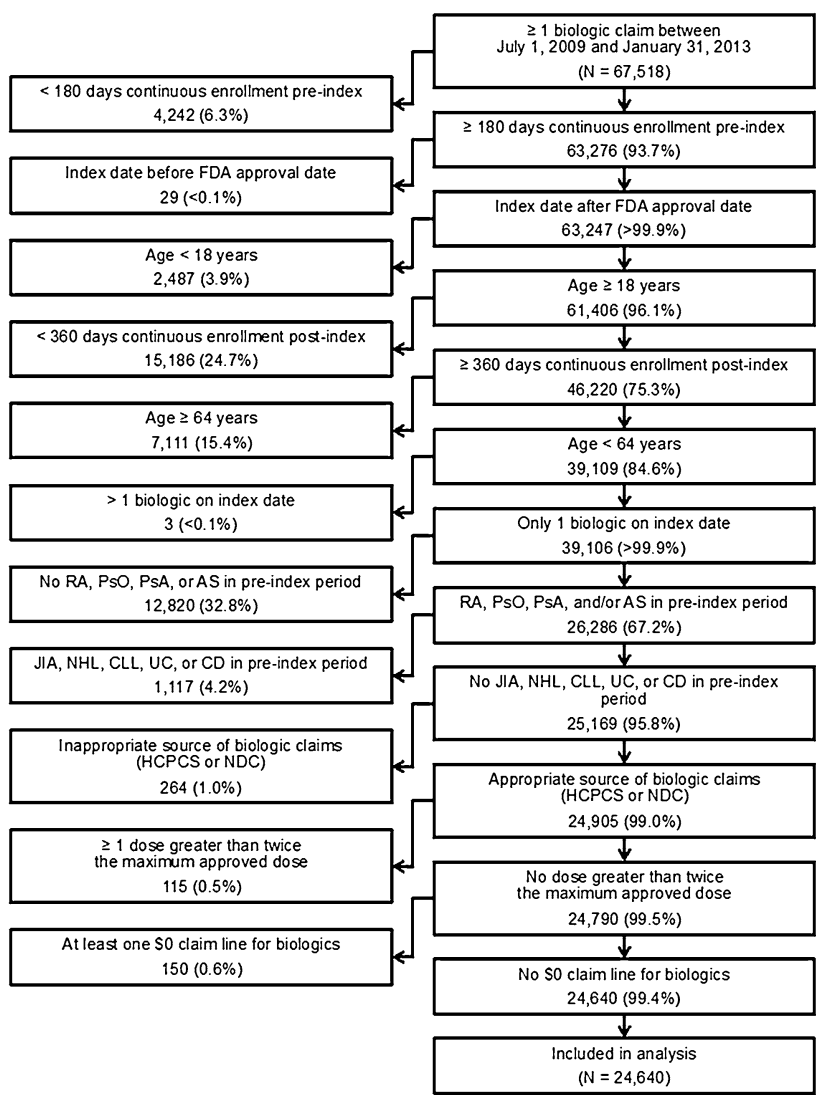

Fig. 1 Study sample attrition. $A S$, ankylosing spondylitis, $C D$ Crohn's disease, $C L L$ chronic lymphocytic leukemia, FDA Food and Drug Administration, HCPCS Healthcare Common Procedure Coding System, JIA juvenile idiopathic arthritis, NDC National Drug Code, NHL non-Hodgkin's lymphoma, PsA psoriatic arthritis, PsO psoriasis, $R A$ rheumatoid arthritis, $U C$ ulcerative colitis 


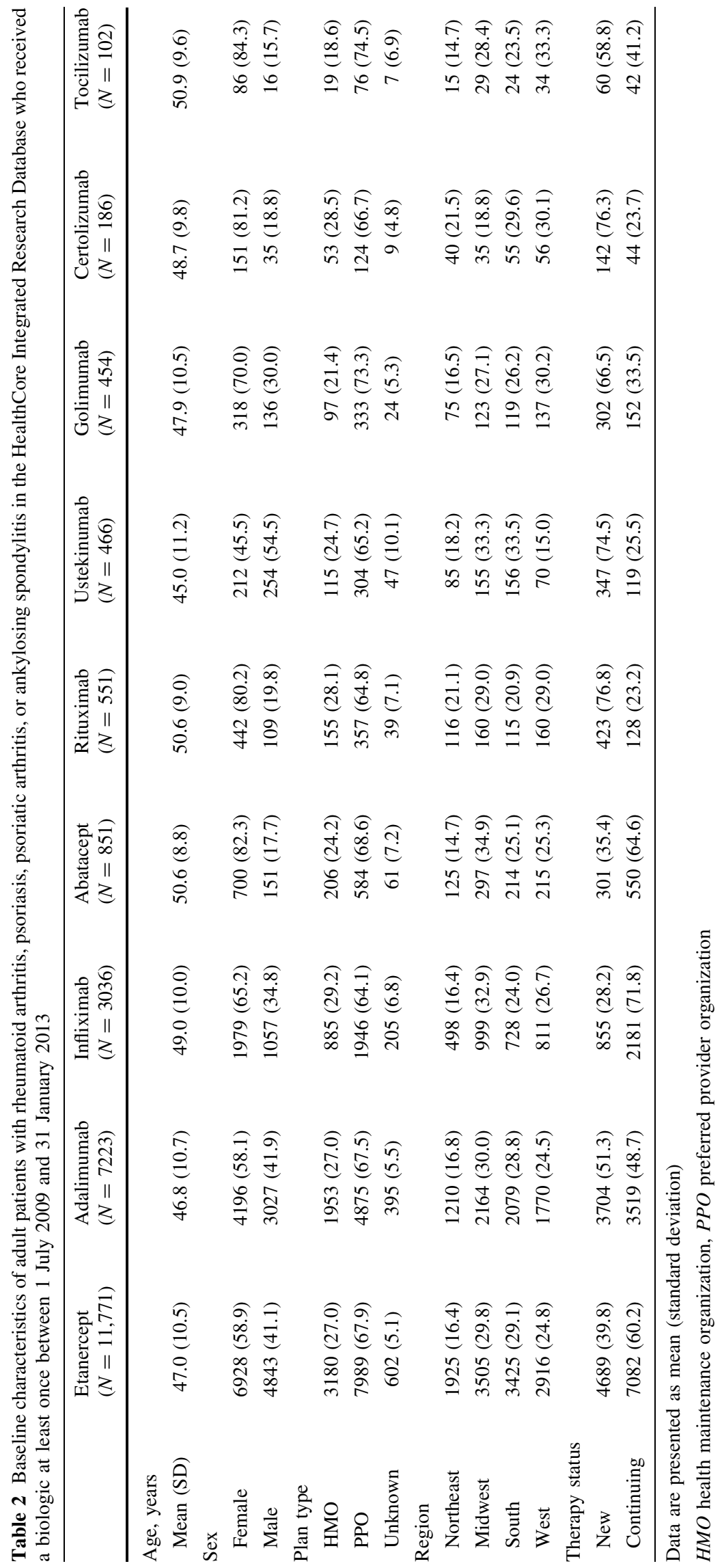




\subsection{Biologic Costs per Treated Patient in the First Year Post-Index}

The 1-year biologic cost per treated patient across all four indications for biologics with these indications approved in the USA was as follows: etanercept \$US24,859; adalimumab \$US26,537; and infliximab \$US26,468. Table 3 shows the 1-year biologic cost for each of the approved indications for each biologic.

Total biologic cost per treated patient for adalimumab and infliximab relative to etanercept is shown in Fig. 2. Cost per treated patient across all four approved indications was $7 \%$ greater for adalimumab than for etanercept and $6 \%$ greater for infliximab than for etanercept. Cost per treated patient for each indication or combination of conditions ranged from $7 \%$ lower to $16 \%$ greater for adalimumab versus etanercept and from $5 \%$ greater to $23 \%$ greater for infliximab versus etanercept.

The analyses of biologic cost per treated patient were repeated separately for new patients (Table 4) and continuing patients (Table 5). Costs for etanercept across indications were similar between new biologic users and continuing biologic users ( $0.2 \%$ difference). By contrast, the cost per treated patient in the first year post-index for adalimumab and infliximab was 10.6 and $25.1 \%$ greater, respectively, for continuing patients than for new patients.

With regards to specific indications, the TNF inhibitors etanercept, adalimumab, infliximab, and golimumab generally had higher costs per treated patient than non-TNF inhibitors in rheumatoid arthritis, and the TNF inhibitors had lower costs per treated patient than non-TNF inhibitors in psoriasis. The TNF inhibitors were the only available biologics for psoriatic arthritis and ankylosing spondylitis during the time period of the study, and etanercept had lower costs per treated patient than the other TNF inhibitors for either indication.

\subsection{Treatment Patterns}

Treatment patterns across all four approved indications and combinations of indications for etanercept, adalimumab, and infliximab were as follows (Fig. 3a): persistent with no treatment gaps, 52, 49, and $67 \%$, respectively; restarted after a >45-day gap, 23, 21, and $12 \%$, respectively; switched to another biologic, 12,13 , and $11 \%$, respectively; and discontinued biologic therapy, 14, 18, and $10 \%$, respectively. Thus, treatment was either persistent or restarted after a $>45$-day treatment gap for more than twothirds of patients whose index biologic was etanercept (75\%), adalimumab (70\%), or infliximab (79 \%). Similar treatment patterns for etanercept, adalimumab, and infliximab were observed for patients with rheumatoid arthritis (Fig. 3b) or psoriasis (Fig. 3c). For the other biologics,
59-76 \% of patients with rheumatoid arthritis (Fig. 3b) and 64-82 \% of patients with psoriasis (Fig. 3c) were either persistent or restarted after a $>45$-day treatment gap in the first year.

\section{Discussion}

\subsection{Interpretation}

In this analysis of claims data for nearly 25,000 patients in a large health benefits organization in the USA, nearly $90 \%$ of index biologic claims for patients with rheumatoid arthritis, psoriatic arthritis, psoriasis, or ankylosing spondylitis were for etanercept, adalimumab, or infliximab. Etanercept had lower biologic costs in the first year postindex than adalimumab or infliximab across all four conditions combined; in patients with the individual conditions of rheumatoid arthritis, psoriatic arthritis, or ankylosing spondylitis; and in patients with combinations of the aforementioned conditions. Adalimumab had lower biologic costs in the first year post-index than etanercept or infliximab in patients with psoriasis. Mean costs for other biologics in the first year post-index were numerically lower than for etanercept, adalimumab, or infliximab in patients with rheumatoid arthritis, but these results are difficult to interpret because the sample sizes for the other biologics were much smaller. We did not calculate the 1-year biologic costs across all four indications and combinations for the other biologics because they were not approved for all of the indications in the analysis.

Costs per treated patient in the first year post-index were similar between new patients and continuing patients who received etanercept. For patients who received any other index biologic, the costs per treated patient in the first year post-index were numerically much higher (approximately \$US1000-6500) for continuing patients than for new patients. Immunogenicity to adalimumab and infliximab has been reported to result in decreased efficacy over time $[14,16]$, and the dose of these biologics is often escalated over time in rheumatoid arthritis to maintain efficacy [6, 10, 24, 40-45]. In addition, rates of persistence are higher in continuing patients than in new patients for any indication across all biologics. Thus, the numerically higher costs per treated patient among patients continuing any biologic except etanercept compared with patients who were new to these biologics may have been related to the use of higher and more doses in the patients who were continuing therapy.

To allow for an examination of diagnosis claims preindex, patients were required to have at least 180 days of continuous enrollment in the plan before their index biologic claim. A majority of patients $(56 \%)$ were continuing 


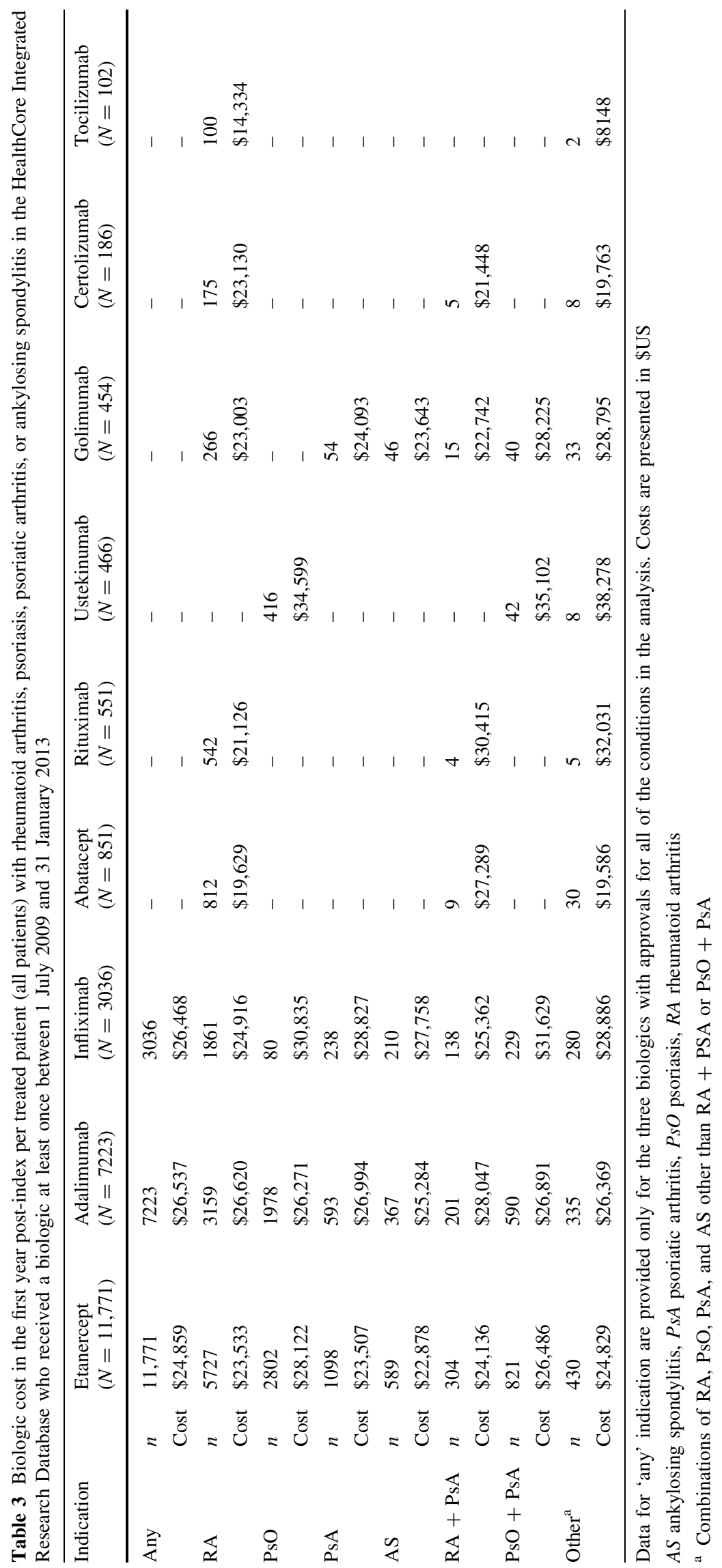




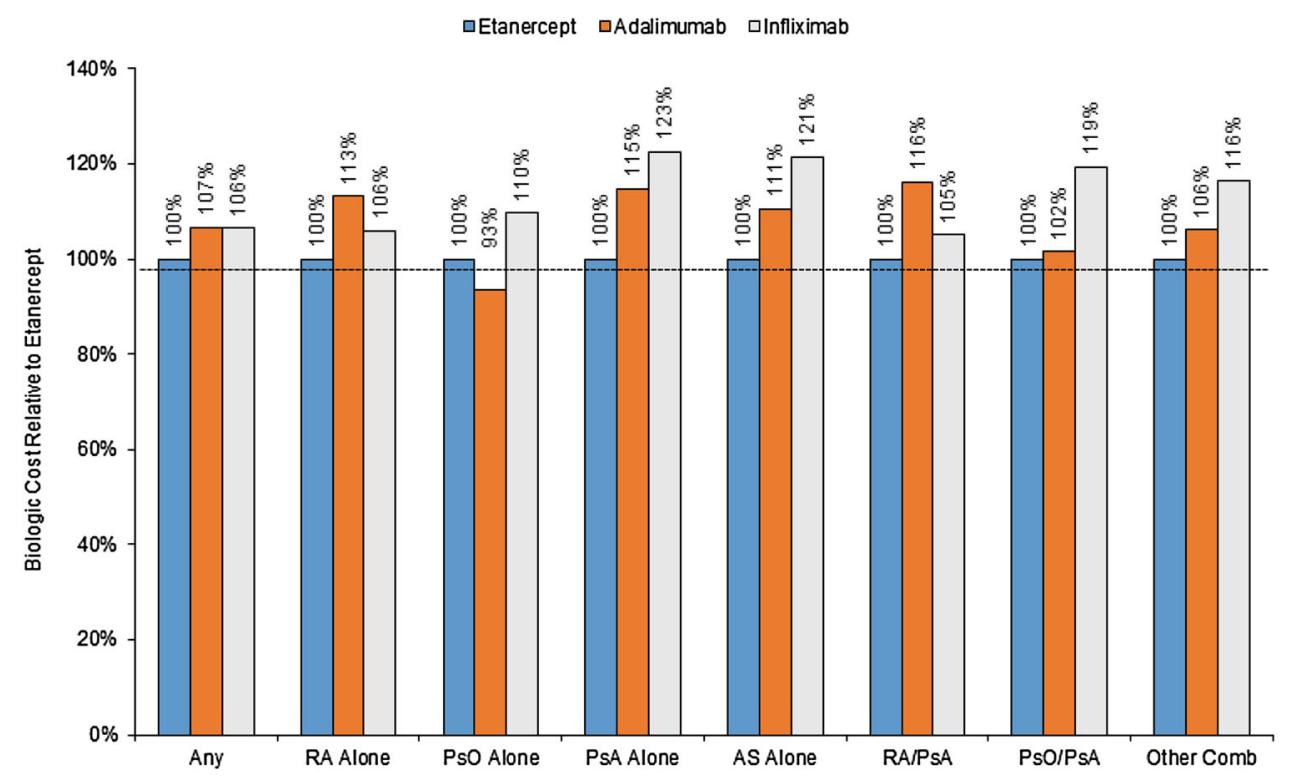

Fig. 2 1-year biologic cost per treated patient relative to etanercept (all patients). The figure includes the three biologics that are approved for use in rheumatoid arthritis, psoriatic arthritis, psoriasis, or ankylosing spondylitis. Data are presented for the 360-day post-index period among adult patients in the HealthCore Integrated Research Database based on index biologic claims that occurred between 1 July 2009 and 31 January 2013. Costs across all four approved indications and combinations of indications were $7 \%$ greater for adalimumab than for etanercept and $6 \%$ greater for infliximab than for etanercept. Costs for each indication or combination of conditions ranged from $7 \%$ lower to $16 \%$ greater for adalimumab vs. etanercept, and from $5 \%$ greater to $23 \%$ greater for infliximab vs. etanercept. $A S$ ankylosing spondylitis, Comb combinations, PsA psoriatic arthritis, $P s O$ psoriasis, $R A$ rheumatoid arthritis therapy with a biologic they had received in the pre-index period. Post-index, more than two-thirds of patients either were persistent on their index biologic or restarted their index biologic after a $>45$-day treatment gap if the index biologic was etanercept $(75 \%)$, adalimumab $(70 \%)$, or infliximab $(79 \%)$.

These findings are similar to those of several previous analyses that used similar methods with other claims databases [20-27] and showed that etanercept had lower costs than adalimumab or infliximab across the four conditions. Unlike the previous studies, which reviewed claims data through 2009, 2010, or 2011, this study included data through 2013 to provide information that is more reflective of current clinical practice. This study also evaluated data for eight biologics, including those that were not approved until 2009 or 2010 , although the small sample sizes for the newer biologics made it difficult to compare them with the commonly used biologics. This study also used a large geographically diverse database of claims information from the largest health benefits organization in the USA, including HMOs, point-of-service plans, PPOs, consumer-directed health plans, and indemnity plans. Thus, the results of this analysis may be generalized to privately insured patients, which included the majority of the US population during the time of this analysis [46].

\subsection{Study Limitations}

Each cohort may have differed in important ways that could not be identified or measured in this study, such as duration of prior biologic treatment for ongoing therapy, reasons for choosing an index biologic, reasons for treatment modifications, and clinical response to the biologic. For example, some biologics (rituximab and tocilizumab) were only indicated for use in patients for whom another biologic had failed previously during the time periods of this study, which may have comprised a different patient population. Diagnosis codes on claims are proxies for actual diagnoses and can be miscoded, over-coded, or under-coded; these errors were unlikely to differ across groups. Selection bias could occur with the study design requirement that patients had 180 days of continuous enrollment prior to and 360 days of continuous enrollment following initiation of biologic therapy; therefore, the study population could be healthier than the total population of patients in the claims database. The current study aimed to estimate real-world cost comparisons across subgroups given the varying characteristics across each subgroup and did not purport to test causal relationships between individual drug use and costs. As such, study findings may have differed if the treatments had been given to patients with similar characteristics as in randomized trials. Finally, 


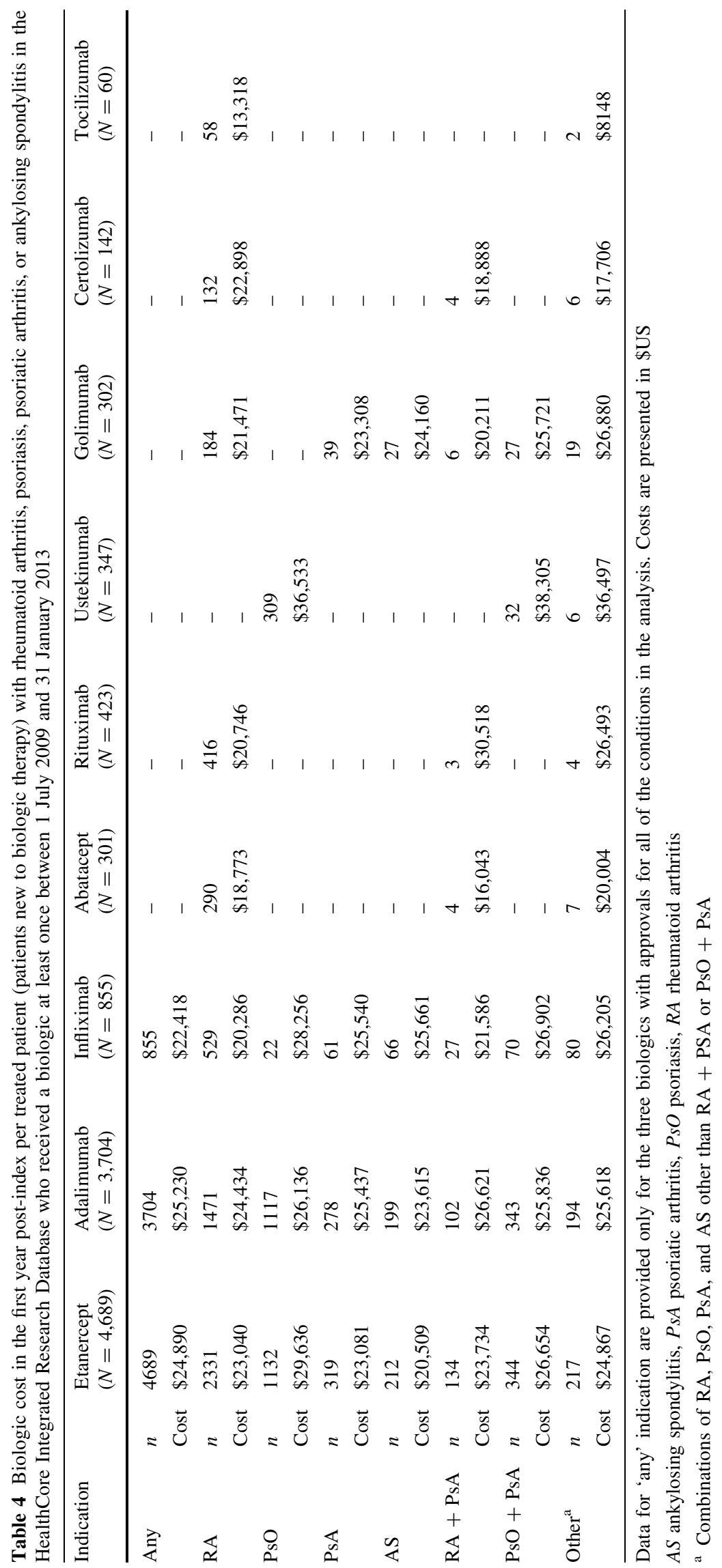




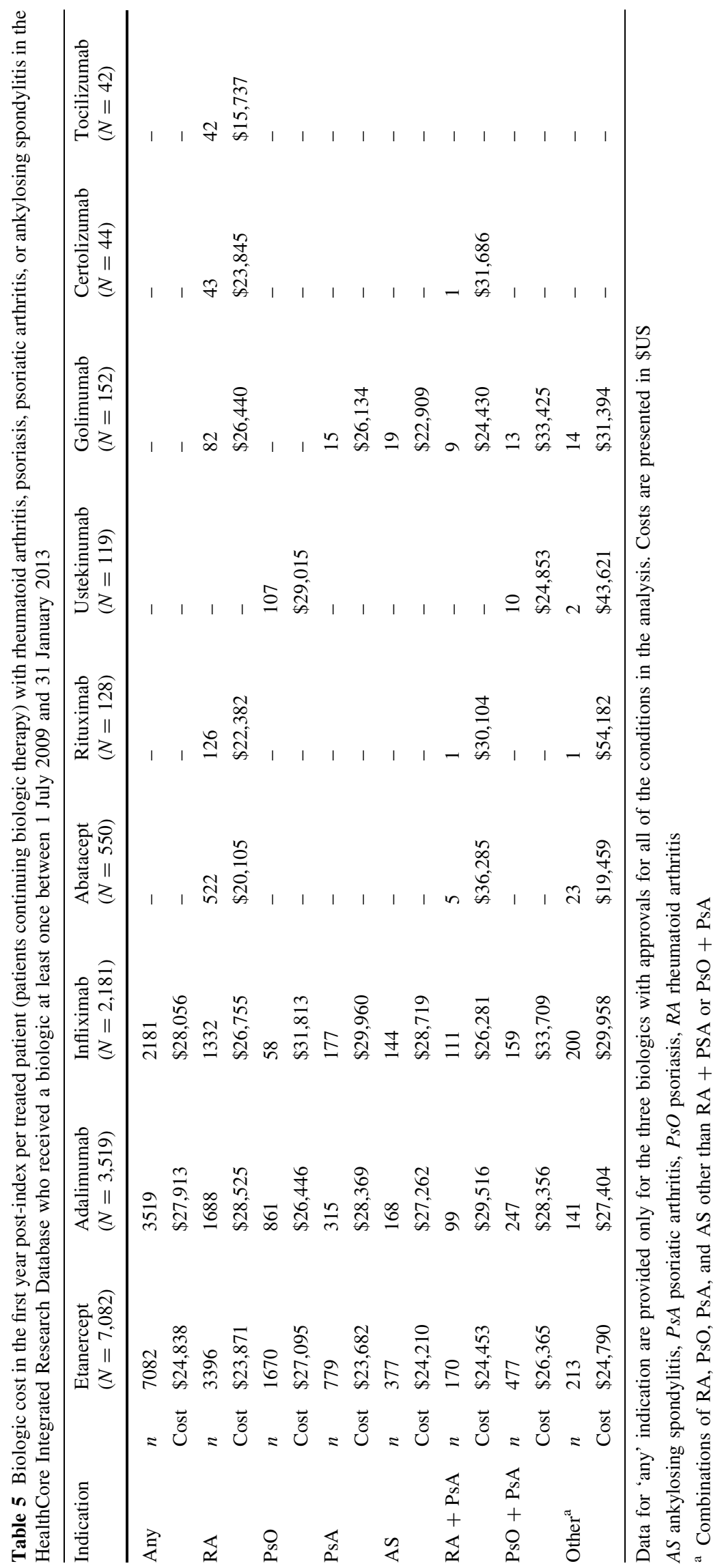


Fig. 3 Treatment patterns in the 1 -year post-index period: a all four indications;

b rheumatoid arthritis; c psoriasis. Data are presented for the 360-day post-index period among adult patients in the HealthCore Integrated Research Database based on index biologic claims that occurred between 1 July 2009 and 31 January 2013. ${ }^{\mathrm{a} B i o l o g i c s}$ that were not approved for the indication (or for all of the conditions in the first panel) are excluded from the figure. Treatment was persistent or restarted after a $>45$-day treatment gap for more than two-thirds of patients whose index biologic was etanercept, adalimumab, or infliximab. For the other biologics, 24-41\% of patients with rheumatoid arthritis and 18-36\% of patients with psoriasis either switched to another biologic or discontinued biologic therapy completely in the first year

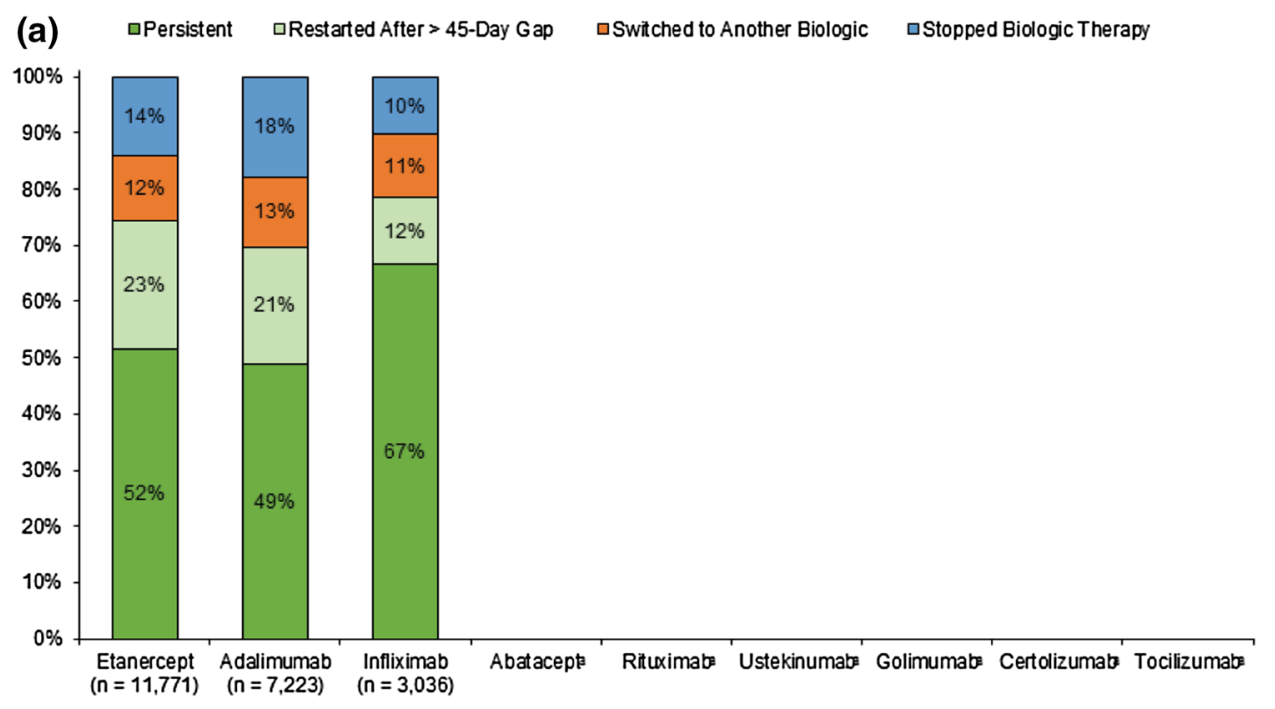

(b) $\quad$ Persistent $\square$ Restarted After > 45-Day Gap $\square$ Switched to Another Biologic $\square$ Stopped Biologic Therapy

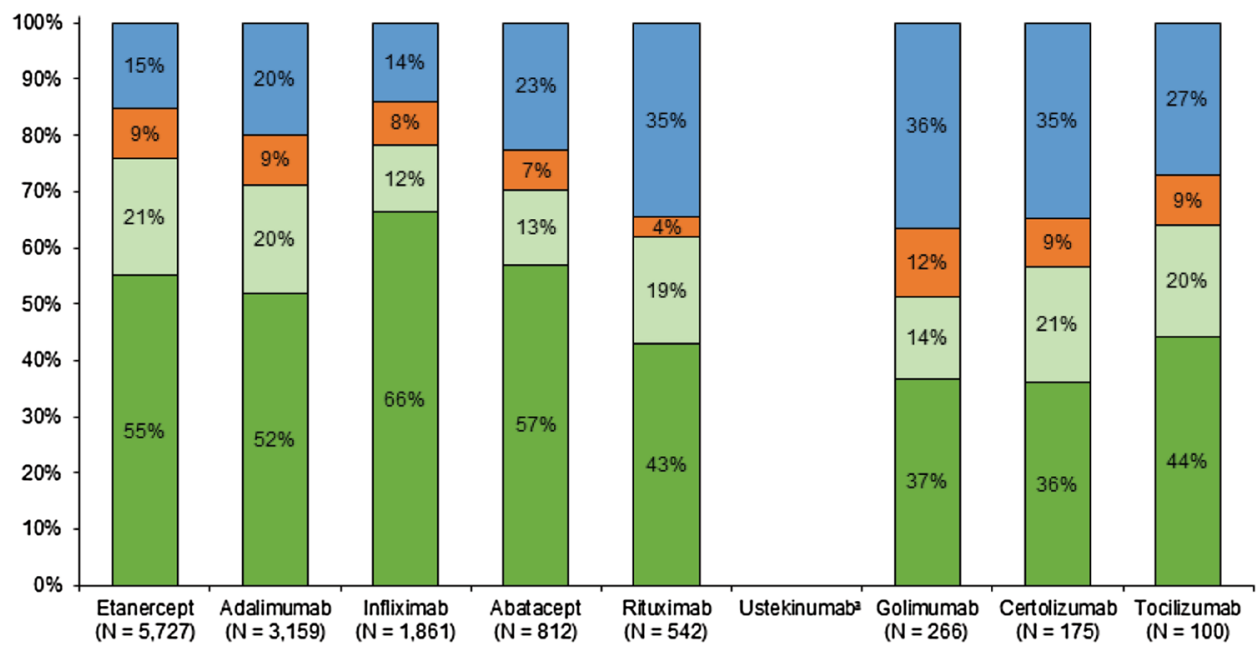

(c) $\quad$ Persistent $\square$ Restarted After > 45-Day Gap $\square$ Switched to Another Biologic $\square$ Stopped Biologic Therapy

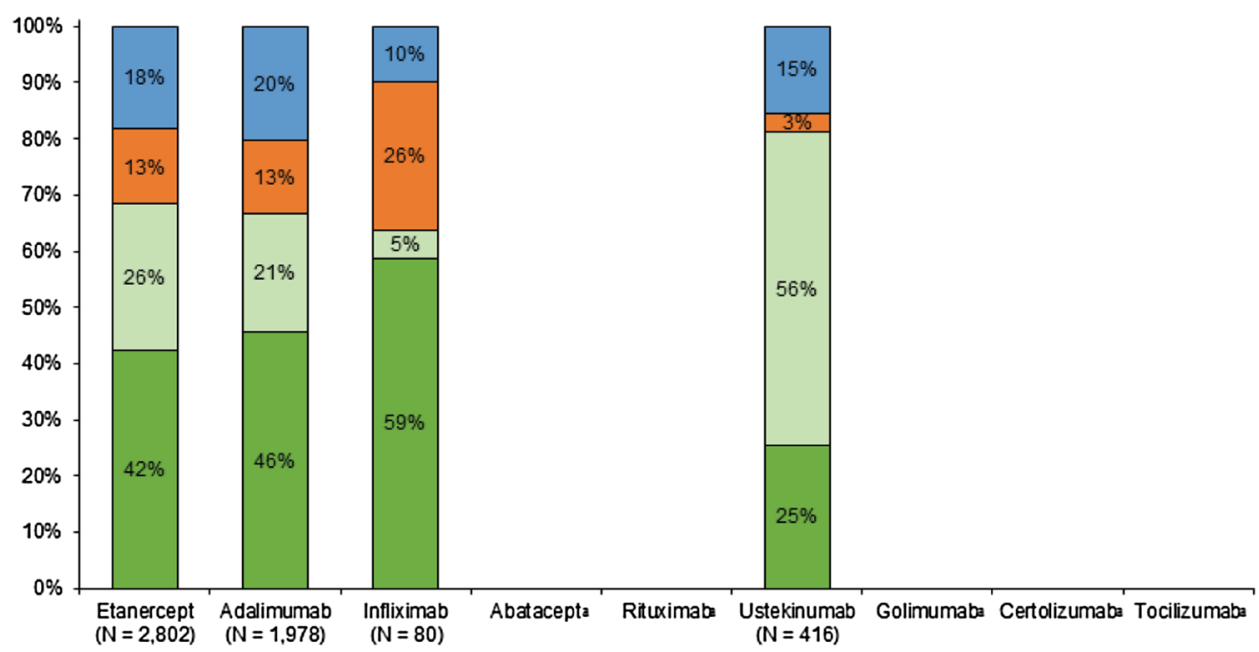


this study used publicly available, commonly used sources for costs, including WAC for drug costs and the Medicare Fee Schedule for administration costs. Actual costs to payers may vary depending on the negotiated drug price between manufacturers and health plans, accounting for various discounts and rebates. Additionally, costs may change for individual biologics at different times. Thus, the use of a different data cutoff date for WAC could have influenced the total estimated cost per treated patient for a given biologic. Administration costs in the Medicare Fee Schedule may differ from those paid for commercially insured patients.

\section{Conclusions}

In this analysis of claims data from a large health benefits organization in the USA, $90 \%$ of patients with rheumatoid arthritis, psoriasis, psoriatic arthritis, and/or ankylosing spondylitis received etanercept, adalimumab, or infliximab as the index biologic. Biologic costs per treated patient in the first year post-index for these three biologics were as follows: across all four conditions, \$US24,859 (etanercept), \$US26,537 (adalimumab), and \$US26,468 (infliximab); rheumatoid arthritis, \$US23,533, \$US26,620, and \$US24,916, respectively; psoriasis, \$US28,122, \$US26,271, and \$US30,835, respectively; psoriatic arthritis, \$US23,507, \$US26,994, and \$US28,827, respectively; and ankylosing spondylitis, \$US22,878, \$US25,284, and $\$$ US27,758, respectively. For each of these biologics, the cost per patient with a combination of these conditions was consistent with the cost per patient for the individual conditions. These findings are similar to those of several previous cost analyses assessing different populations, demonstrating the external validity of the results from the previous studies, both over time and across large populations.

Acknowledgments The authors acknowledge David J. Harrison for his contributions to study conception and design and data analysis and interpretation. Jessica $\mathrm{Ma}, \mathrm{PhD}$, (Amgen Inc.) and Jonathan Latham (on behalf of Amgen Inc.) provided medical writing support.

Author Contributions TG, NS, GD, DHT, and DFE made substantial contributions to study conception and design; TG and GD made substantial contributions to acquisition of data; TG, NS, GD, DHT, and DFE made substantial contributions to analysis and interpretation of data. TG, NS, GD, DHT, and DFE revised the article critically for important intellectual content. TG, NS, GD, DHT, and DFE approved the final version of this article to be published.

\section{Compliance with Ethical Standards}

Ethical approvals This study utilized de-identified patient-level data and thus did not require Institutional Review Board review.
Informed consent The data for this analysis were accessed and analyzed in a manner that complied with The Health Insurance Portability and Accountability Act of 1996 (HIPAA) regulations, including those related to privacy and security of individually identifiable health information. Individuals' informed consent was not required as this study employed de-identified data.

Conflict of interest NS is an employee and stockholder of Amgen Inc. DHT is a former employee and stockholder of Amgen Inc. TG, GD, and DFE received research grants from Amgen Inc. for this study.

Funding This research was funded by Immunex Corporation, a wholly owned subsidiary of Amgen Inc.

Open Access This article is distributed under the terms of the Creative Commons Attribution-NonCommercial 4.0 International License (http://creativecommons.org/licenses/by-nc/4.0/), which permits any noncommercial use, distribution, and reproduction in any medium, provided you give appropriate credit to the original author(s) and the source, provide a link to the Creative Commons license, and indicate if changes were made.

\section{References}

1. Meier FM, Frerix M, Hermann W, Müller-Ladner U. Current immunotherapy in rheumatoid arthritis. Immunotherapy. 2013;5:955-74.

2. Day MS, Nam D, Goodman S, Su EP, Figgie M. Psoriatic arthritis. J Am Acad Orthop Surg. 2012;20:28-37.

3. Raychaudhuri SP, Deodhar A. The classification and diagnostic criteria of ankylosing spondylitis. J Autoimmun. 2014;48-49:128-33.

4. Kircik LH, Del Rosso JQ. Anti-TNF agents for the treatment of psoriasis. J Drugs Dermatol. 2009;8:546-59.

5. ORENCIA ${ }^{\circledR}$ (abatacept) Prescribing Information. Princeton: Bristol-Myers Squibb Company; 2015.

6. Humira ${ }^{\circledR}$ (adalimumab) Prescribing Information. North Chicago: AbbVie Inc.; 2014.

7. CIMZIA $^{\circledR}$ (certolizumab pegol) Prescribing Information. Smyrna: UCB, Inc.; 2013.

8. Enbrel ${ }^{\circledR}$ (etanercept) Prescribing Information. Thousand Oaks: lmmunex Corporation; 2015.

9. SIMPONI ${ }^{\circledR}$ (golimumab) Prescribing Information. Horsham: Janssen Biotech, Inc.; 2014.

10. Remicade ${ }^{\circledR} \quad$ (infliximab) Prescribing Information. Malvern: Janssen Biotech, Inc.; 2015.

11. RITUXAN ${ }^{\circledR}$ (rituximab) Prescribing Information. South San Francisco: Genentech, Inc.; 2014.

12. ACTEMRA ${ }^{\circledR}$ (tocilizumab) Prescribing Information. South San Francisco: Genentech, Inc.; 2014.

13. STELARA ${ }^{\circledR}$ (ustekinumab) Prescribing Information. Horsham: Janssen Biotech, Inc.; 2014.

14. Bartelds GM, Krieckaert CL, Nurmohamed MT, van Schouwenburg PA, Lems WF, Twisk JW, et al. Development of antidrug antibodies against adalimumab and association with disease activity and treatment failure during long-term follow-up. JAMA. 2011;305:1460-8.

15. Krieckaert CL, Jamnitski A, Nurmohamed MT, Kostense PJ, Boers M, Wolbink G. Comparison of long-term clinical outcome with etanercept treatment and adalimumab treatment of rheumatoid arthritis with respect to immunogenicity. Arthritis Rheum. 2012;64:3850-5. 
16. Pascual-Salcedo D, Plasencia C, Ramiro S, Nuño L, Bonilla G, Nagore D, et al. Influence of immunogenicity on the efficacy of long-term treatment with infliximab in rheumatoid arthritis. Rheumatology (Oxford). 2011;50:1445-52.

17. Donahue KE, Jonas D, Hansen RA, Roubey R, Jonas B, Lux LJ, et al. Drug therapy for rheumatoid arthritis in adults: an update. Comparative Effectiveness Review No. 55. (Prepared by RTIUNC Evidence-based Practice Center under Contract No. 290-020016-I.) AHRQ Publication No. 12-EHC025-EF. Rockville: Agency for Healthcare Research and Quality; 2012. Available from: http://effectivehealthcare.ahrq.gov/index.cfm/search-forguides-reviews-and-reports/?productid=1042\&pageaction= displayproduct. Accessed 23 Apr 2013.

18. Donahue KE, Jonas D, Hansen RA, Roubey R, Jonas B, Lux LJ, et al. Drug therapy for psoriatic arthritis in adults: update of a 2007 report. 12-EHC024-EF. Rockville: Agency for Healthcare Research and Quality; 2012. Available from: http://effectivehealthcare.ahrq.gov/ ehc/products/464/1043/arthritis-psoriatic-executive-120424.pdf. Accessed 07 Aug 2015.

19. Maxwell LJ, Zochling J, Boonen A, Singh JA, Veras MM, Tanjong Ghogomu E et al. TNF-alpha inhibitors for ankylosing spondylitis. Cochrane Database Syst Rev. 2015;4:CD005468.

20. Bonafede M, Joseph GJ, Princic N, Harrison DJ. Annual acquisition and administration cost of biologic response modifiers per patient with rheumatoid arthritis, psoriasis, psoriatic arthritis, or ankylosing spondylitis. J Med Econ. 2013;16:1120-8.

21. Bonafede MM, Gandra SR, Watson C, Princic N, Fox KM. Cost per treated patient for etanercept, adalimumab, and infliximab across adult indications: a claims analysis. Adv Ther. 2012;29:234-48.

22. Schabert VF, Watson C, Gandra SR, Goodman S, Fox KM, Harrison DJ. Annual costs of tumor necrosis factor inhibitors using real-world data in a commercially insured population in the United States. J Med Econ. 2012;15:264-75.

23. Schabert VF, Watson C, Joseph GJ, Iversen P, Burudpakdee C, Harrison DJ. Costs of tumor necrosis factor blockers per treated patient using real-world drug data in a managed care population. J Manag Care Pharm. 2013;19:621-30.

24. Joyce AT, Gandra SR, Fox KM, Smith TW, Pill MW. National and regional dose escalation and cost of tumor necrosis factor blocker therapy in biologic-naïve rheumatoid arthritis patients in US health plans. J Med Econ. 2014;17:1-10.

25. Howe A, Eyck LT, Dufour R, Shah N, Harrison DJ. Treatment patterns and annual drug costs of biologic therapies across indications from the Humana commercial database. J Manag Care Spec Pharm. 2014;20:1236-44.

26. Wu N, Lee YC, Shah N, Harrison DJ. Cost of biologics per treated patient across immune-mediated inflammatory disease indications in a pharmacy benefit management setting: a retrospective cohort study. Clin Ther. 2014;36(1231-41):e3.

27. Bonafede M, Joseph GJ, Shah N, Princic N, Harrison DJ. Cost of tumor necrosis factor blockers per patient with rheumatoid arthritis in a multistate Medicaid population. Clinicoecon Outcomes Res. 2014;6:381-8.

28. Ollendorf DA, Klingman D, Hazard E, Ray S. Differences in annual medication costs and rates of dosage increase between tumor necrosis factor-antagonist therapies for rheumatoid arthritis in a managed care population. Clin Ther. 2009;31:825-35.

29. Curtis JR, Chastek B, Becker L, Quach C, Harrison DJ, Yun H, et al. Cost and effectiveness of biologics for rheumatoid arthritis in a commercially insured population. J Manag Care Spec Pharm. 2015;21:318-29.

30. Curtis JR, Schabert VF, Harrison DJ, Yeaw J, Korn JR, Quach C, et al. Estimating effectiveness and cost of biologics for rheumatoid arthritis: application of a validated algorithm to commercial insurance claims. Clin Ther. 2014;36:996-1004.

31. Curtis JR, Schabert VF, Yeaw J, Korn JR, Quach C, Harrison DJ, et al. Use of a validated algorithm to estimate the annual cost of effective biologic treatment for rheumatoid arthritis. J Med Econ. 2014; 17:555-66.

32. Malottki K, Barton P, Tsourapas A, Uthman AO, Liu Z, Routh K, et al. Adalimumab, etanercept, infliximab, rituximab and abatacept for the treatment of rheumatoid arthritis after the failure of a tumour necrosis factor inhibitor: a systematic review and economic evaluation. Health Technol Assess. 2011;15:1-278.

33. Bonafede M, Fox KM, Watson C, Princic N, Gandra SR. Treatment patterns in the first year after initiating tumor necrosis factor blockers in real-world settings. Adv Ther. 2012;29:664-74.

34. Carter CT, Changolkar AK, Scott McKenzie R. Adalimumab, etanercept, and infliximab utilization patterns and drug costs among rheumatoid arthritis patients. J Med Econ. 2012;15:332-9.

35. Li P, Blum MA, Von Feldt J, Hennessy S, Doshi JA. Adherence, discontinuation, and switching of biologic therapies in medicaid enrollees with rheumatoid arthritis. Value Health. 2010;13:805-12.

36. Yeaw J, Watson C, Fox KM, Schabert VF, Goodman S, Gandra SR. Treatment patterns following discontinuation of adalimumab, etanercept, and infliximab in a US managed care sample. Adv Ther. 2014;31:410-25.

37. Chastek B, Fox KM, Watson C, Gandra SR. Etanercept and adalimumab treatment patterns in psoriatic arthritis patients enrolled in a commercial health plan. Adv Ther. 2012;29:691-7.

38. Chastek B, Fox KM, Watson C, Kricorian G, Gandra SR. Psoriasis treatment patterns with etanercept and adalimumab in a United States health plan population. J Dermatolog Treat. 2013;24:25-33.

39. Wasser T, Wu B, Ycas J, Tunceli O, Cziraky MJ. Comparison of commercial insurance databases to census data for age, gender and geographic region in the United States. Value Health. 2013;16:A22-3.

40. Agarwal SK, Maier AL, Chibnik LB, Coblyn JS, Fossel A, Lee R, et al. Pattern of infliximab utilization in rheumatoid arthritis patients at an academic medical center. Arthritis Rheum. 2005;53:872-8.

41. Moots RJ, Haraoui B, Matucci-Cerinic M, van Riel PL, Kekow J, Schaeverbeke T, et al. Differences in biologic dose-escalation, non-biologic and steroid intensification among three anti-TNF agents: evidence from clinical practice. Clin Exp Rheumatol. 2011;29:26-34.

42. Ogale S, Hitraya E, Henk HJ. Patterns of biologic agent utilization among patients with rheumatoid arthritis: a retrospective cohort study. BMC Musculoskelet Disord. 2011;12:204.

43. Bonafede MM, Gandra SR, Fox KM, Wilson KL. Tumor necrosis factor blocker dose escalation among biologic naïve rheumatoid arthritis patients in commercial managed-care plans in the 2 years following therapy initiation. J Med Econ. 2012;15:635-43.

44. Schabert VF, Bruce B, Ferrufino CF, Globe DR, Harrison DJ, Lingala B, et al. Disability outcomes and dose escalation with etanercept, adalimumab, and infliximab in rheumatoid arthritis patients: a US-based retrospective comparative effectiveness study. Curr Med Res Opin. 2012;28:569-80.

45. Cannon GW, DuVall SL, Haroldsen CL, Caplan L, Curtis JR, Michaud K, et al. Persistence and dose escalation of tumor necrosis factor inhibitors in US veterans with rheumatoid arthritis. J Rheumatol. 2014;41:1935-43.

46. Smith JC, Medalia C. U.S. Census Bureau, Current Population Reports, P60-250, Health Insurance Coverage in the United States. Washington, DC: US Government Printing Office; 2013. p. 2014. 